\title{
FTIR Investigation of Nitrogen Monoxide and Carbon Monoxide Influence on Human Blood Coagulation
}

\author{
Elena Aleksakhina ${ }^{1 \mathbb{D}}$, Irina Tomilova ${ }^{2(\mathbb{D})}$, Dmitry Merkushev ${ }^{3 \mathbb{D}}$, Ekaterina Bobishkina ${ }^{3}$, \\ Yuriy Marfin 3,* iD \\ 1 Department of Chemistry, Physics, Mathematics; Ivanovo State Medical Academy, Sheremetevsky pr., 8, Ivanovo, \\ Russian Federation, 153012 \\ 2 Department of Biochemistry, Ivanovo State Medical Academy, Sheremetevsky pr., 8, Ivanovo, Russian Federation, \\ 153012 \\ 3 Department of Inorganic Chemistry, Ivanovo State University of Chemical Technology, Sheremetevsky pr., 10, Ivanovo, \\ Russian Federation, 153010 \\ * Correspondence: marfin@isuct.ru (Y.M);
}

Scopus Author ID 26432032600

Received: 25.09.2021; Revised: 30.10.2021; Accepted: 3.11.2021; Published: 21.11.2021

\begin{abstract}
The formation of fibrin clots determines the characteristics of blood plasma coagulation. It is known that small molecules like nitrogen and carbon monoxides have a toxic effect at high concentrations due to the competitive binding to hemoglobin, preventing further oxygen transfer. The mechanisms of intoxication with these gases have been extensively studied in the literature, but there is little information on their effects on other vital processes. In particular, blood coagulation parameters have not been studied, although prolonged exposure to relatively low concentrations of gases can cause significant pathological changes. In this paper, the characteristics of the fibrin-polymer after coagulation of a blood plasma sample under conditions of pretreatment with gases were studied using FTIRspectroscopy. The changes in the vibrations of individual bonds and fragments in the Amide I and Amide $\mathrm{B}$ regions are shown and analyzed. It was established that at concentrations of $\mathrm{CO}$ exceeding the endogenous levels, the connector $\alpha$-helix unfolds and $\beta$-structures form, leading to the loss of part of the hydrate shell, the formation of a fibrin clot with a disordered structure of higher density due to an increase in its hydrophobicity. For cases where samples were treated with NO gas, the degree of aggregation of the fibrin clot from plasma incubated with nitroglycerin was one-quarter less than the original, the proportion of $\alpha$-helices was not reduced, and there were no disordered structures in the clot. This may indicate a lower clot density and probably easier lysis of the one.
\end{abstract}

Keywords: nitrogen monoxide; carbon monoxide; fibrin; blood coagulation; vibrational spectroscopy (C) 2021 by the authors. This article is an open-access article distributed under the terms and conditions of the Creative Commons Attribution (CC BY) license (https://creativecommons.org/licenses/by/4.0/).

\section{Introduction}

It is well known that certain small molecules can regulate enzyme activity in vivo and in vitro by direct protein intermolecular contacts or by changing the structure of the hydration shell [1]. Both carbon monoxide (CO) and nitrogen monoxide (NO) form in the human body, regulate many processes and act similarly as vasodilators, anti-inflammatory, and cytoprotective agents [2-5]. However, there are little data on the effect of these substances on the process of vascular-platelet and coagulation hemostasis [6,7].

The mechanism of the regulatory action of $\mathrm{CO}$ at physiological concentrations is based on the interaction with heme groups of proteins. In particular, $\mathrm{CO}$ activates guanylate cyclase and regulates the level of cyclic guanosine monophosphate in the cell $[8,9]$. Still, there are 
several ways of the non-endogenous appearance of $\mathrm{CO}$ in the blood plasma, like inhalation of tobacco smoke and anthropogenic carbon monoxide poisoning. Therefore, no less important is its toxic effect due to the formation of carboxyhemoglobin [10-16]. In these cases, the processes of oxygen transport and cellular respiration are blocked, which can have lethal consequences for a living organism [17].

Another toxic action of $\mathrm{CO}$ is based on its redox properties. It has been proven that $\mathrm{CO}$ affects the redox potential of biological systems. The rate and direction of electron transfer between $\mathrm{CO}$ and proteins are strongly related to monoxide concentration and accompanied by a change in the activity of proteins and the cell as a whole [18,19].

Currently, fluorescence spectroscopy and infrared Fourier spectroscopy methods are actively used to analyze the structure of biomolecules [20], aggregation, intermolecular interactions in proteins, changes in the secondary structure, and spatial orientation of protein biomolecules at a quantitative level. The latter is especially important for blood coagulation, both at the stage of fibrin formation (from fibrinogen, coagulation factor I) and lysis [21,22], and directly related to changes in the secondary structure and orientation of fibrin fibers [23]. Traditionally, several separate groups of bands are distinguished in the IR spectra of proteins: amide A, amide B, amides I, II, III. It is believed that the characteristic regions of amide B and amides I and II are the most sensitive to protein conformational changes and enzymatic activity.

In this work, we studied the effect of nitrogen and carbon monoxides on human blood plasma coagulation and the effect of small molecule additions on the possibility of thrombus formation [24].

\section{Materials and Methods}

In this work, a drainage platelet-free citrate blood plasma from the Regional Vascular Center of Ivanovo was used [25].

The influence of $\mathrm{CO}$ on the supramolecular structure of fibrin was studied by passing carbon monoxide through the platelet-free human citrate plasma. The gas was obtained by the reaction between formic acid (chemically pure, Khimmed, Russia) and sulfuric acid (98\%, Khimmed). The gas bubbling rate was $1.2 \mathrm{ml} / \mathrm{min}$; the studied flow times were 5 and $30 \mathrm{~min}$.

It is known that endogenous production of $\mathrm{CO}$ in the human body averages $16.4 \mu \mathrm{mol}$ / h, reaching $500 \mu \mathrm{mol}(12 \mathrm{ml})$ per day, which corresponds to an average of $0.01 \mu \mathrm{mol} / \mathrm{ml}$ of plasma. The solubility of the gas in the investigated biological liquid was assessed by the absorption coefficient (coefficient of solubility) - the value that indicates the volume of gas that can be dissolved at $700 \mathrm{mmHg}(0.921 \mathrm{~atm}, 0.0933 \mathrm{MPa})$ in $1 \mathrm{ml}$ of liquid at $0{ }^{\circ} \mathrm{C}$. The absorption coefficient is directly proportional to the gas pressure and inversely proportional to the temperature and the amount of substances dissolved in the biological fluid. Considering that the coefficient of dissolution of carbon monoxide in human blood plasma is $0.17 \mathrm{ml} /(\mathrm{ml}$ - $\mathrm{kPa}$ ) [26], the maximum concentration of $\mathrm{CO}$ in the blood plasma will be $0.12 \mu \mathrm{mol} / \mathrm{ml}$ after 5 minutes and $0.72 \mu \mathrm{mol} / \mathrm{ml}$ after 30 minutes of bubbling, which, respectively, is 10 and 60 times higher than the physiological concentration. In clinical practice, a 10-fold increase in the concentration of carbon monoxide in the inhaled air causes headache, nausea, impaired coordination of movements, dizziness. A 60 -fold increase in the concentration of carbon monoxide in the inhaled air causes an intense headache, confusion, short-term loss of consciousness (lipothymia), shortness of breath during exertion, and vomiting [27].

The effect of NO was studied in platelet-free human citrate plasma, incubated for 30 min with nitroglycerin $(\mathrm{c}=1.09 \mu \mathrm{mol} / \mathrm{ml})$ at $37^{\circ} \mathrm{C}$. 
The FTIR method (infrared spectroscopy with Fourier distribution) was used to register changes in the secondary structure and orientation of the initial fibrin and fibrin treated with carbon and nitrogen monoxides. IR spectra were recorded on the TENSOR-27 Bruker Optics Fourier spectrometer (Germany). Normalization by reduction to the baseline and processing of the spectra was performed using the OPUS-6 software (Bruker, Germany).

The IR spectra were obtained using undeformed human fibrin clots made by coagulation of human platelet-free plasma. The coagulation was controlled by absorption spectra using the CM-2203 spectrofluorometer (SOLAR, Belarus) [28]. The fibrin clots were laid out on KRS glass and dried at room temperature to a dry film.

\section{Results and Discussion}

It is known that the characteristic peaks of Amide I at 1620-1624 $\mathrm{cm}^{-1}$ and $1690-1696$ $\mathrm{cm}^{-1}$ correspond to antiparallel $\beta$-layers [18]. Parallel $\beta$-layers result in peaks at $1628-1635 \mathrm{~cm}^{-}$ 1 and 1680-1690 $\mathrm{cm}^{-1}$. The $\alpha$-helices and the disordered structures have close spectral wavelengths of $1650-1655 \mathrm{~cm}^{-1}$ and $1645-1652 \mathrm{~cm}^{-1}$, respectively. It is also known that extensive formation of additional antiparallel $\beta$-layers is most often observed in protein aggregation $[29,30]$.

In this work, the measured IR spectra indicate that the initial fibrin in the frequency range of Amide I has an asymmetric vibration band at $1653 \mathrm{~cm}^{-1}$. The band's position indicates that the clot is formed by polymeric fibrin filaments, which $\alpha$-helical connectors form monomers. The presence of a lower intensity band at $1626 \mathrm{~cm}^{-1}$ indicates a small number of antiparallel $\beta$-layers. The pronounced changes in IR spectra of fibrin clots from plasma samples saturated with carbon monoxide and nitroglycerin may be seen in Figure 1.

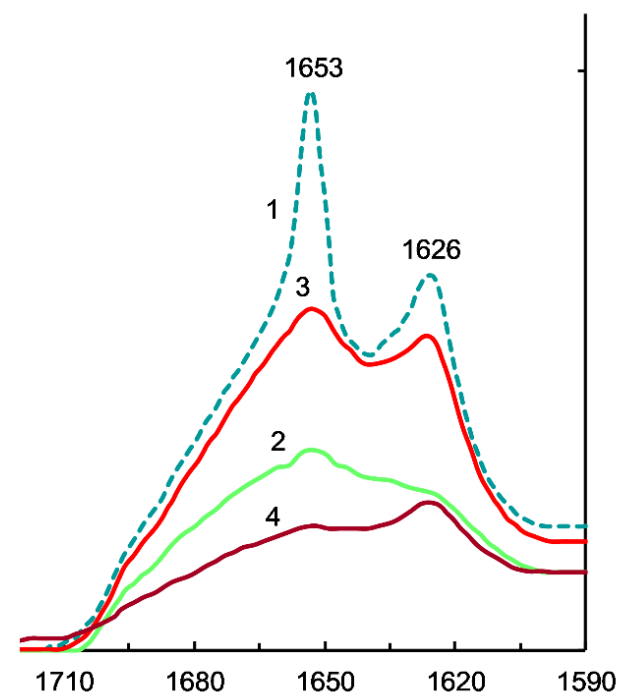

Figure 1. FT IR - spectra of fibrin in the region of Amide I. 1 - initial fibrin; 2- fibrin obtained from plasma incubated with nitroglycerin $100 \mu \mathrm{g} / \mathrm{ml} ; 3$ - fibrin obtained from plasma bubbled with CO for 5 min; 4- fibrin obtained from plasma bubbled with $\mathrm{CO}$ for $30 \mathrm{~min}$.

The treatment of blood plasma with $\mathrm{NO}$ and $\mathrm{CO}$ gases leads to a decrease in the intensity of vibrations in the Amide I region, broadening of the bands of individual vibrations, and general destructuring of the spectrum. In the case of CO treatment, the $\alpha$-helix protein chain vibration band decreases most intensively, and the vibration intensities are redistributed in favor of antiparallel $\beta$-layers. Changes in the spectra are due to a violation of the secondary structure of the protein associated with the formation of fibrin clots. 
FTIR was used to determine the quantitative content of different types of secondary structure in fibrin (Figure 2, Table 1, Table 2) [31].

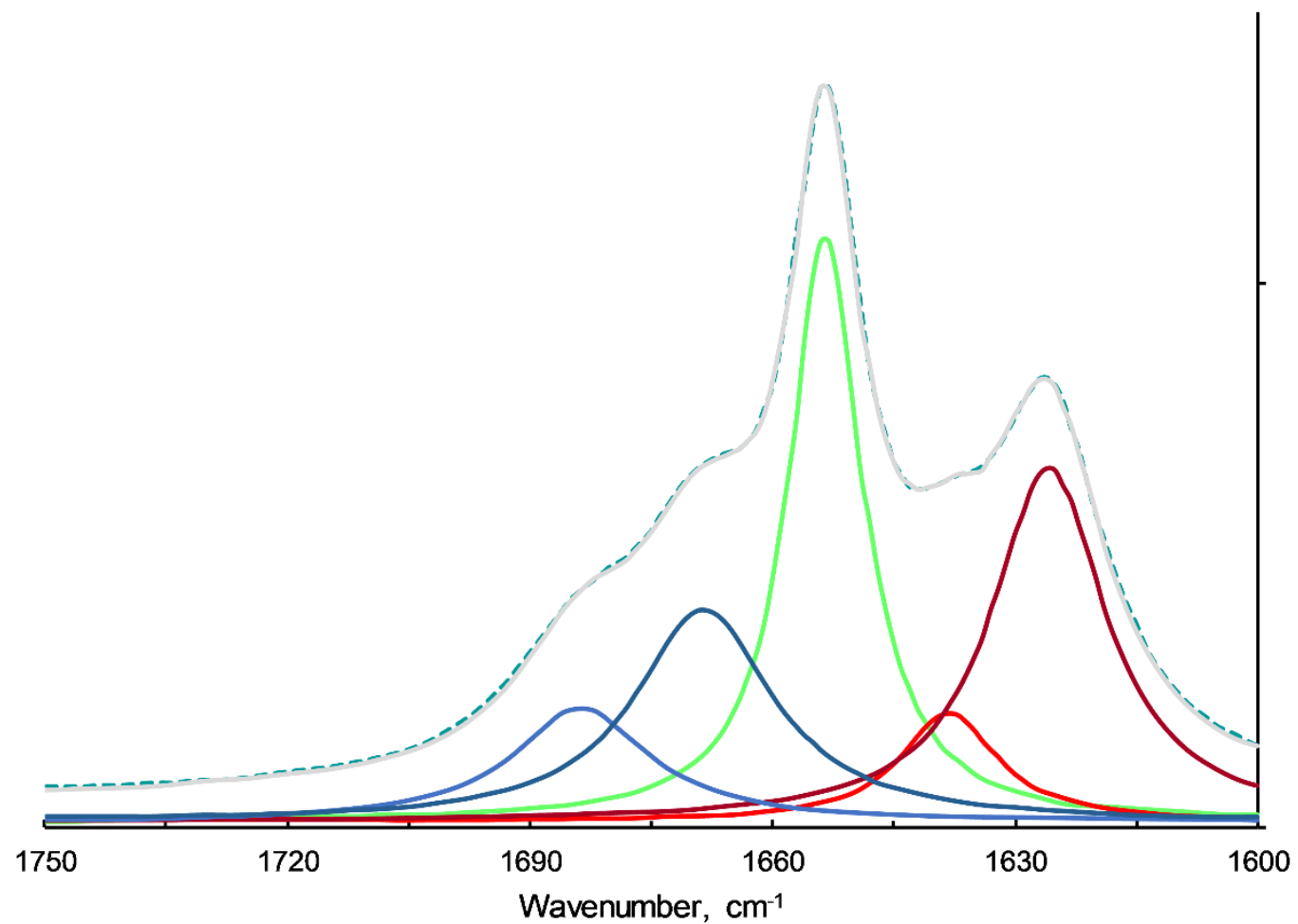

Figure 2. Decomposition of the FTIR - spectral Amide I peak of the initial fibrin into elements of the secondary structure.

Table 1. Content of different types of secondary structure in fibrin [18,31].

\begin{tabular}{|c|c|c|c|c|}
\hline Position, $\mathbf{c m}^{-1}$ & Intensity, a.u. & Width, $\mathbf{c m}^{-1}$ & $\begin{array}{c}\text { Integrated } \\
\text { intensity, a.u. }\end{array}$ & $\begin{array}{c}\text { Secondary structure } \\
\text { type }\end{array}$ \\
\hline \multicolumn{5}{|c|}{ Initial fibrin } \\
\hline 1625.18 & 1.58 & 17.22 & 42.72 & antiparallel $\beta$-layers \\
\hline 1638.17 & 0.49 & 14.37 & 10.98 & parallel $\beta$-layers \\
\hline 1653.33 & 2.61 & 10.93 & 44.79 & $\alpha$-helix \\
\hline 1668.47 & 0.95 & 20.58 & 30.64 & $\beta$-turn \\
\hline 1683.68 & 0.51 & 20.30 & 16.11 & $\beta$-turn \\
\hline \multicolumn{5}{|c|}{ Local residual standard deviation: 0.07} \\
\hline \multicolumn{5}{|c|}{ Fibrin obtained from plasma bubbled with $\mathrm{CO}$ for $5 \mathrm{~min}$} \\
\hline 1625.25 & 0.64 & 24.75 & 24.92 & antiparallel $\beta$-layers \\
\hline 1650.11 & 0.48 & 36.70 & 27.81 & unordered structures \\
\hline 1669.14 & 0.28 & 28.57 & 12.39 & $\beta$-turn \\
\hline 1686.02 & 0.13 & 24.06 & 4.78 & $\beta$-turn \\
\hline \multicolumn{5}{|c|}{ Local residual standard deviation: 0.03} \\
\hline \multicolumn{5}{|c|}{ Fibrin obtained from plasma bubbled with $\mathrm{CO}$ for $30 \mathrm{~min}$} \\
\hline 1626.06 & 1.54 & 26.69 & 64.57 & antiparallel $\beta$-layers \\
\hline 1650.09 & 1.66 & 32.94 & 85.99 & unordered structures \\
\hline 1670.53 & 0.67 & 29.31 & 30.92 & $\beta$-turn \\
\hline 1685.54 & 0.35 & 27.94 & 14.78 & $\beta$-turn \\
\hline \multicolumn{5}{|c|}{ Local residual standard deviation: 0.08} \\
\hline \multicolumn{5}{|c|}{ Fibrin obtained from plasma incubated with nitroglycerin $100 \mu \mathrm{g} / \mathrm{ml}$} \\
\hline 1622.51 & 0.61 & 34.89 & 33.22 & antiparallel $\beta$-layers \\
\hline 1633.12 & 0.21 & 22.25 & 7.42 & parallel $\beta$-layers \\
\hline 1653.74 & 0.95 & 37.88 & 56.80 & $\alpha$-helix \\
\hline 1678.37 & 0.55 & 50.74 & 44.12 & $\beta$-turn \\
\hline
\end{tabular}

Table 2. Percentages of the main types of secondary structures in the fibrin clot.

\begin{tabular}{|c|c|c|c|c|} 
& $\begin{array}{c}\text { antiparallel } \\
\boldsymbol{\beta} \text {-layers }\end{array}$ & $\begin{array}{c}\text { parallel } \\
\boldsymbol{\beta} \text {-layers }\end{array}$ & $\begin{array}{c}\text { unordered } \\
\text { structures }\end{array}$ & $\boldsymbol{\alpha}$-helix \\
\hline Initial fibrin & 29.41 & 7.56 & 0 & 30.84
\end{tabular}




\begin{tabular}{c|c|c|c|c} 
& $\begin{array}{c}\text { antiparallel } \\
\boldsymbol{\beta} \text {-layers }\end{array}$ & $\begin{array}{c}\text { parallel } \\
\boldsymbol{\beta} \text {-layers }\end{array}$ & $\begin{array}{c}\text { unordered } \\
\text { structures }\end{array}$ & $\boldsymbol{\alpha}$-helix \\
\hline $\begin{array}{c}\text { Fibrin obtained from plasma incubated } \\
\text { with nitroglycerin 100 } \boldsymbol{\mu g} / \mathbf{m l}\end{array}$ & 22.16 & 4.95 & 0 & 37.90 \\
\hline $\begin{array}{c}\text { Fibrin obtained from plasma bubbled } \\
\text { with CO for 5 min }\end{array}$ & 30.64 & 0 & 34.20 & 0 \\
\hline $\begin{array}{c}\text { Fibrin obtained from plasma bubbled } \\
\text { with CO for 30 min }\end{array}$ & 31.39 & 0 & 41.80 & 0
\end{tabular}

The data in Tables 1 and 2 let us conclude that fibrin clots obtained during the coagulation of plasma saturated with $\mathrm{CO}$ and in the presence of nitroglycerin are protein aggregates, which supramolecular structures are significantly different from the initial fibrin. It is clear that investigated gases have different mechanisms of action on the samples.

The number of disordered structures increases upon the coagulation of $\mathrm{CO}$-saturated plasma as well as the number of antiparallel $\beta$-layers. This is a result of polymeric fibrin aggregation and the unwinding of $\alpha$-helical connectors [18]. Protein aggregation is usually accompanied by the emergence of hydrophobic amino acid radicals on the surface. This is the reason why the aggregation of $\beta$-structures formed during the deployment of $\alpha$-helices in fibrin leads to a decrease in the volume of the deformed clot [32]. Hydrophobic interactions can displace water from the near- and interprotein space, decreasing the volume and increasing the density of the protein clot.

The aggregation degree of a fibrin clot incubated from nitroglycerin-doped plasma is $25 \%$ less than the initial one. The proportion of $\alpha$-helices does not decrease, and there are no disordered structures in the clot. This may indicate a lower density of the clot and, probably, its easier lysis [33].

The structure of fibrinogen determines the structural properties of fibrin [32,34]. It is known that fibrinogen is a dimeric protein of blood plasma weighing $340 \mathrm{kDa}$, consisting of three pairs of polypeptide chains: $\mathrm{A} \alpha, \mathrm{B} \beta$, and $\gamma$, connected by disulfide bonds. Two distant globular parts of fibrinogen are connected to the central globular part by two $17 \mathrm{~nm}$ long supercoils formed by three (or four) $\alpha$-helices. Its polymerization into fibrin begins with fibrinopeptides $\mathrm{A}$ and $\mathrm{B}$ cleavage from the N-terminal part of the $\mathrm{A} \alpha$ and $\mathrm{B} \beta$ chains of fibrinogen under the action of thrombin. In this case, the fibrinogen monomer is transformed into a fibrin monomer with the same structural properties. The monomeric fibrin then polymerizes to form a network of fibrin filaments in which the monomers bind both covalently and non-covalently. In our experiment, we treated not a clot of fibrin, but platelet-free plasma, in which an external mechanism then triggered the coagulation process. The observed changes in the supramolecular structure of fibrin are due to changes in the structure of fibrinogen. It is known that the process of enzymatic catalysis is extremely sensitive to the steric and hydration factors; therefore, changes in the supramolecular structure of fibrinogen as a result of exposure to a low molecular weight compound will undoubtedly lead to a change in the kinetic characteristics of the coagulation process both at the stage of thrombus formation and at the stage of its lysis [35].

The spectra of the initial fibrin and fibrin obtained from plasma incubated with NO are identical in the frequency range of Amide B and reveal 5 bands of different intensities: the strong bifurcated band with maxima at 2930 and $2960 \mathrm{~cm}^{-1}$, the weak forked band with maxima at 2873 and $2854 \mathrm{~cm}^{-1}$, and the weak band with a maximum at $3067 \mathrm{~cm}^{-1}$.

Changes in the IR spectra of fibrin treated with carbon monoxide in the frequency range of Amide B are very significant and prove the conclusions drawn from the analysis of changes in characteristic peaks in Amide I. 


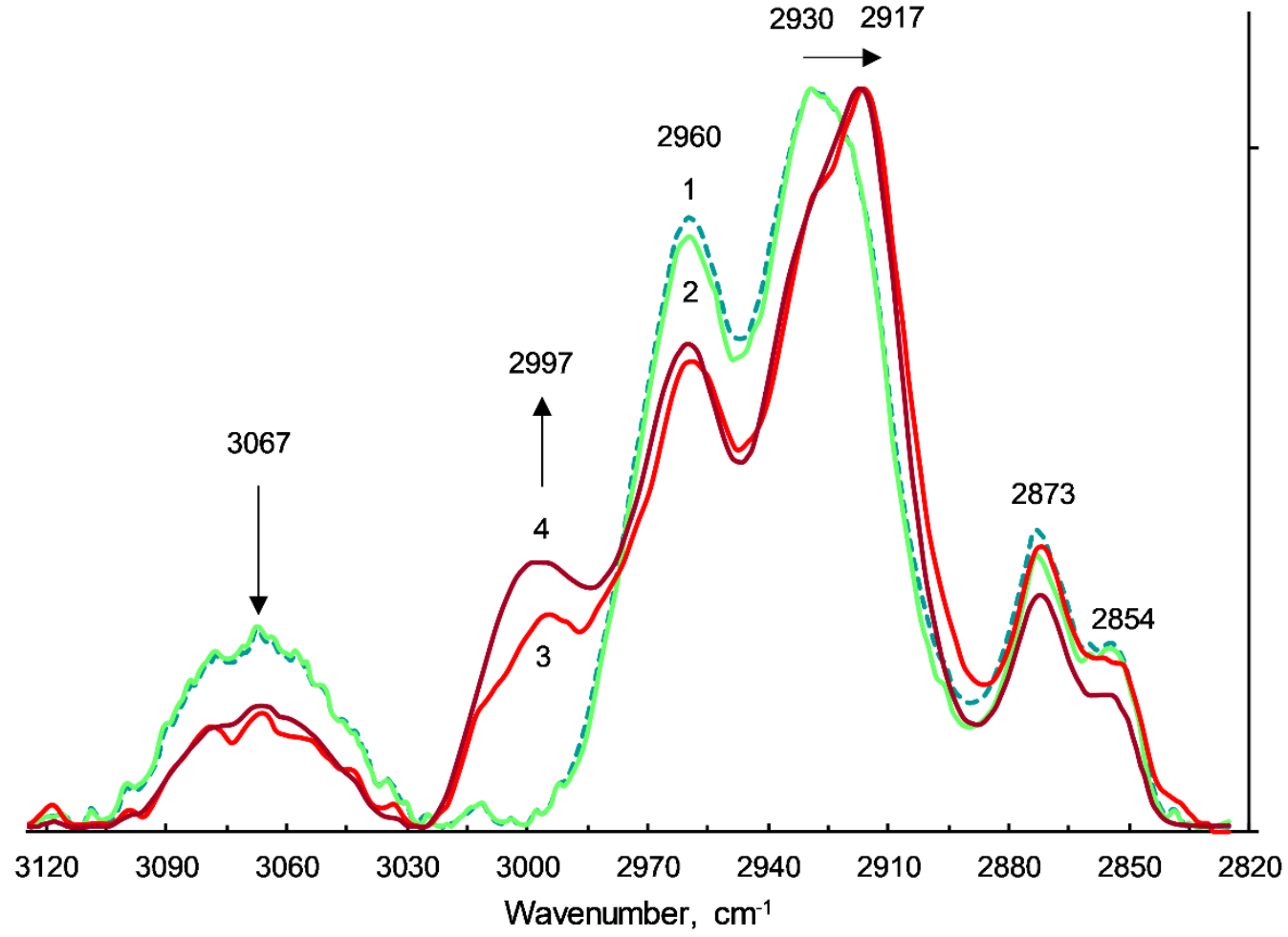

Figure 3. FTIR - spectra of fibrin in the region of Amide B. 1 - initial fibrin; 2 - fibrin obtained from plasma incubated with nitroglycerin $100 \mu \mathrm{g} / \mathrm{ml} ; 3$ - fibrin obtained from plasma bubbled with CO for 5 min; 4 - fibrin obtained from plasma bubbled with $\mathrm{CO}$ for $30 \mathrm{~min}$.

As it can be seen in Figure 3, the band at $3067-3065 \mathrm{~cm}^{-1}$ is assigned to the first overtone vibration of Amide $\mathrm{B}$, which is responsible for conformational changes in protein macromolecules. But on the other side, the data of IR spectroscopy and computer simulation [36] of IR spectra of water and aqueous solutions of ethanol indicate that there is a band in the same range $\left(3000-3100 \mathrm{~cm}^{-1}\right)$ caused by stretching vibrations of $\mathrm{OH}$ - groups, which form very strong hydrogen bonds and connected to each other in associates. It can be concluded that the band at $3067-3065 \mathrm{~cm}^{-1}$ is assigned to the first overtone vibration of Amide B and is responsible for conformational changes. This band is also associated with stretching vibrations of $\mathrm{OH}$ groups of water molecules, which stabilize $\alpha$-helical connections. A decrease in the band's intensity indicates a weakening of hydrogen bonds between the $\mathrm{OH}$ groups of water molecules surrounded by the fibrin backbone. This confirms the earlier assumptions about the violation of the protein structure due to the interaction with gas molecules.

The group of bands in the IR spectra, localized in the region of $2750-3000 \mathrm{~cm}^{-1}$, corresponds to the $\mathrm{C}-\mathrm{H}$ bonds vibrations in the acid alkyl radicals. The band with maxima at 2930 and $2960 \mathrm{~cm}^{-1}$ is responsible for stretching vibrations of $\mathrm{C}-\mathrm{H}$ in alkyl radicals [18].

FTIR spectra of fibrin incubated with carbon monoxide show a band formation at 2997 $\mathrm{cm}^{-1}$ (which refers to asymmetric stretching vibrations of $\mathrm{C}-\mathrm{H}$ alkyl groups), a synchronous decrease in the band at $3067 \mathrm{~cm}^{-1}$, and a bathochromic shift of the band from 2930 to $2917 \mathrm{~cm}^{-}$ 1 . These changes may indicate that the water molecules move away from the peptide backbone due to the $\alpha$-helix $\rightarrow \beta$ - the structure of monomeric fibrin units. An increase in the intensity of the band of asymmetric vibrations of the $\mathrm{C}-\mathrm{H}$ in alkyl groups may indicate the unfolding of radicals and the emergence of hydrophobic radicals on the surface, which will inevitably lead to a change in the enzymatic activity of fibrinogen and fibrin.

Thus, our data indicate that in the presence of $\mathrm{CO}$ (at 10 times higher concentration than the endogenous in blood plasma), irreversible destructive processes begin in fibrin and, 
consequently, fibrinogen. These processes are primarily due to the deployment of the $\alpha$-helical connector and the formation of $\beta$-structures. The following loss of a part of the hydration shell and increase in its hydrophobicity leads to the formation of a clot of the disordered structure of higher density.

\section{Conclusions}

The characteristics of fibrin-polymer after coagulation of blood plasma samples under conditions of their pretreatment with $\mathrm{NO}$ and $\mathrm{CO}$ were studied using FTIR spectroscopy methods. Changes in the vibrations of individual bonds and fragments in the Amide I and Amide $\mathrm{B}$ region were shown and analyzed. It was found that at $\mathrm{CO}$ concentrations exceeding endogenous parameters, the supramolecular structure of fibrin changes. First of all, the $\alpha-$ helical connector deploys, and the $\beta$-structures form. That led to the loss of a part of the hydration shell and was followed by forming a fibrin clot of a disordered structure of higher density due to an increase in its hydrophobicity. The degree of aggregation of a fibrin clot from plasma incubated with nitroglycerin dating NO is one-fourth less than the initial one, while the proportion of $\alpha$-helices does not decrease, and there are no disordered structures in the clot. This may indicate a lower density of the clot and, probably, its easier lysis.

For the first time, the effect of carbon monoxide (II) excess on the mechanism of blood coagulation has been shown. It was found that toxic CO concentrations lead to an irreversible change in the structure of fibrin and fibrinogen. In turn, this leads to a change in the nature of blood coagulation. The information obtained is of interest both for studying the effect of carbon monoxide on the human body and diagnosing pathological conditions against the background of carbon monoxide poisoning.

\section{Funding}

The study was carried out on the center's equipment for collective use of scientific equipment of the Ivanovo State University of Chemistry and Technology. The work was carried out with the financial support of the RFBR grant 18-43-370035 and within the framework of the state assignment of the Ministry of Health of the Russian Federation No. 056-00028-2100 «Functional reserve of hemostasis and blood rheology in hypoxia states under normal and morbid conditions».

\section{Acknowledgments}

The study was carried out using the resources of the Center for Shared Use of Scientific Equipment of the ISUCT (with the support of the Ministry of Science and Higher Education of Russia, No. 075-15-2021-671).

\section{Conflicts of Interest}

The authors declare no conflict of interest. The funders had no role in the study's design, in the collection, analyses, or interpretation of data, in the writing of the manuscript, or in the decision to publish the results.

\section{References}

1. Makshakova, O.; Ermakova, E. Computational Study of Hydrogen-Bonding Complex Formation of Helical Polypeptides with Water Molecule. J. Mol. Struct. THEOCHEM 2010, 942, 7-14, 
https://doi.org/10.1016/j.theochem.2009.11.026.

2. Armstrong, D.; Stratton, R.D. Oxidative Stress and Antioxidant Protection; Wiley 2016; https://books.google.ro/books?hl=en\&lr=\&id=mAT9CgAAQBAJ\&oi=fnd\&pg=PR9\&dq=Oxidative+Stress +and+Antioxidant+Protection\%3B+Wiley, $+2016 \&$ ots $=x d P k d R j E v c \& s i g=H 7 N z 44 V-$

kE8zE1ea9Kb1PqfD618\&redir_esc=y\#v=onepage \&q=Oxidative \%20Stress\%20and\%20Antioxidant $\% 20$ Pro tection\%3B\%20Wiley\%2C\%202016\&f=false.

3. Almeida, A.S.; Figueiredo-Pereira, C.; Vieira, H.L.A. Carbon Monoxide and Mitochondria-Modulation of Cell Metabolism, Redox Response and Cell Death. Front. Physiol. 2015, 6, 33, https://doi.org/10.3389/fphys.2015.00033.

4. Cressatti, M.; Galindez, J.M.; Juwara, L.; Orlovetskie, N.; Velly, A.M.; Eintracht, S.; Liberman, A.; Gornitsky, M.; Schipper, H.M. Characterization and Heme Oxygenase-1 Content of Extracellular Vesicles in Human Biofluids. J. Neurochem. 2021, 157, 2195-2209, https://doi.org/10.1111/jnc.15167.

5. Adach, W.; Olas, B. A. Comparison of Multifunctional Donors of Carbon Monoxide: Their Anticoagulant, Antioxidant, Anti-Aggregatory and Cytotoxicity Activities in an in vitro Model. Nitric Oxide - Biol. Chem. 2020, 97, 20-26, https://doi.org/10.1016/j.niox.2020.01.010.

6. Dessy, C.; Feron, O. Pathophysiological Roles of Nitric Oxide: In the Heart and the Coronary Vasculature. Curr. Med. Chem. Anti-inflamm. Anti-Allergy Agents 2004, 3, 207-216, https://doi.org/10.2174/1568014043355348.

7. Davis, E.; Malig, B.; Broadwin, R.; Ebisu, K.; Basu, R.; Gold, E.B.; Qi, L.; Derby, C.A.; Park, S.K.; Wu, X. (May) Association between Coarse Particulate Matter and Inflammatory and Hemostatic Markers in a Cohort of Midlife Women. Environ. Heal. A Glob. Access Sci. Source 2020, 19, https://doi.org/10.1186/s12940-02000663-1.

8. Olas, B. Carbon Monoxide Is Not Always a Poison Gas for Human Organism: Physiological and Pharmacological Features of CO. Chem. Biol. Interact. 2014, 222, 37-43, https://doi.org/10.1016/j.cbi.2014.08.005.

9. Mannaioni, P.F.; Vannacci, A.; Masini, E. Carbon Monoxide: The Bad and the Good Side of the Coin, from Neuronal Death to Anti-Inflammatory Activity. Inflamm. Res. 2006, 55, 261-273, https://doi.org/10.1007/s00011-006-0084-y.

10. Prockop, L.D.; Chichkova, R.I. Carbon Monoxide Intoxication: An Updated Review. J. Neurol. Sci. 2007, 262, 122-130, https://doi.org/10.1016/j.jns.2007.06.037.

11. Veronesi, A.; Pecoraro, V.; Zauli, S.; Ottone, M.; Leonardi, G.; Lauriola, P.; Trenti, T. Use of Carboxyhemoglobin as a Biomarker of Environmental CO Exposure: Critical Evaluation of the Literature. Environ. Sci. Pollut. Res. 2017, 24, 25798-25809, https://doi.org/10.1007/s11356-017-0270-1.

12. Oliverio, S.; Varlet, V. Total Blood Carbon Monoxide: Alternative to Carboxyhemoglobin as Biological Marker for Carbon Monoxide Poisoning Determination. J. Anal. Toxicol. 2019, 43, 79-87, https://doi.org/10.1093/jat/bky084.

13. Simonsen, C.; Magnusdottir, S.O.; Andreasen, J.J.; Wimmer, R.; Rasmussen, B.S.; Kjærgaard, B.; Maltesen, R.G. Metabolic Changes during Carbon Monoxide Poisoning: An Experimental Study. J. Cell. Mol. Med. 2021, 25, 5191-5201, https://doi.org/10.1111/jcmm.16522.

14. Mao, Q.; Kawaguchi, A.T.; Mizobata, S.; Motterlini, R.; Foresti, R.; Kitagishi, H. Sensitive Quantification of Carbon Monoxide in vivo Reveals a Protective Role of Circulating Hemoglobin in CO Intoxication. Commun. Biol. 2021, 4, https://doi.org/10.1038/s42003-021-01880-1.

15. Abdel salam, M.E.; Elawady, E.H.; Khater, A.S.; Eweda, S.A.; Abd el moneam, M.H. Neuropsychiatric Sequelae of Acute Carbon Monoxide Poisoning: The Predictive Role of Neuron Specific Enolase and Glial Fibrillary Acidic Protein. Neurotoxicology 2021, 85, 115-120, https://doi.org/10.1016/j.neuro.2021.05.003.

16. Bhatia, V.; Elnagary, L.; Dakshinamurti, S. Tracing the Path of Inhaled Nitric Oxide: Biological Consequences of Protein Nitrosylation. Pediatr. Pulmonol. 2021, 56, 525-538, https://doi.org/10.1002/ppul.25201.

17. Feng, D.; Cao, K.; Zou, J.; Bloom, M.S.; Lin, S.; Yu, Y.; Yu, H.; Zhou, Y.; Liu, R.Q.; Hu, L.W.; et al. Associations between Size-Fractioned Particulate Matter and Left Ventricular Voltage: A Panel Study among Healthy Young Adults in Southern China. Atmos. Environ. 2021, 254, https://doi.org/10.1016/j.atmosenv.2021.118395.

18. Manning, M.C. Use of Infrared Spectroscopy to Monitor Protein Structure and Stability. Expert Rev. Proteomics 2005, 2, 731-743, https://doi.org/10.1586/14789450.2.5.731.

19. Nielsen, V.G. Carbon Monoxide Inhibits the Anticoagulant Activity of Mojave Rattlesnake Venoms Type A and B. J. Thromb. Thrombolysis 2019, 48, 256-262, https://doi.org/10.1007/s11239-019-01887-w.

20. Zanuy, D.; Puiggalí-Jou, A.; Conflitti, P.; Bocchinfuso, G.; Palleschi, A.; Alemán, C. Aggregation Propensity of Therapeutic Fibrin-Homing Pentapeptides: Insights from Experiments and Molecular Dynamics Simulations. Soft Matter 2020, 16, 10169-10179, https://doi.org/10.1039/d0sm00930j.

21. Bramanti, E.; Benedetti, E.; Sagripanti, A.; Papineschi, F.; Benedetti, E. Determination of Secondary Structure of Normal Fibrin from Human Peripheral Blood; John Wiley ,\& Sons, Inc. Biopoly 1997, 41; https://doi.org/10.1002/(SICI)1097-0282(19970415)41:5<545::AID-BIP6>3.0.CO;2-M.

22. Litvinov, R.I.; Pieters, M.; de Lange-Loots, Z.; Weisel, J.W. Fibrinogen and Fibrin. In Subcellular 
Biochemistry, Springer Science and Business Media B.V. 2021; Vol. 96, pp. 471-501, https://link.springer.com/chapter/10.1007/978-3-030-58971-4_15.

23. Tutwiler, V.; Maksudov, F.; Litvinov, R.I.; Weisel, J.W.; Barsegov, V. Strength and Deformability of Fibrin Clots: Biomechanics, Thermodynamics, and Mechanisms of Rupture. Acta Biomater. 2021, 31, 355-369, https://doi.org/10.1016/j.actbio.2021.06.046.

24. Neo, S.; Kok, S.S.; Tan, K.; Kumar, S. Factors That Predict Delayed Neurological Sequelae of Carbon Monoxide Poisoning from a 10-Year Clinico-Radiological Review. Ann. Acad. Med. Singapore 2020, 49, 331-336, https://pubmed.ncbi.nlm.nih.gov/32582910/.

25. Spinella, P.C.; Sniecinski, R.M.; Trachtenberg, F.; Inglis, H.C.; Ranganathan, G.; Heitman, J.W.; Szlam, F.; Danesh, A.; Stone, M.; Keating, S.M.; et al. Effects of Blood Storage Age on Immune, Coagulation, and Nitric Oxide Parameters in Transfused Patients Undergoing Cardiac Surgery. Transfusion 2019, 59, 12091222, https://doi.org/10.1111/trf.15228.

26. Neto, G.A.; Itizoyanagihara, J.; Turri, F. A Carbon Monoxide Transport Model of the Human Respiratory System Applied to Urban Atmosphere Exposure Analysis. J. Brazilian Soc. Mech. Sci. Eng. 2008, 30, 253260, https://doi.org/10.1590/s1678-58782008000300011.

27. Guzman, J.A. Carbon Monoxide Poisoning. Crit. Care Clin. 2012, 28, 537-548, https://www.mayoclinic.org/diseases-conditions/carbon-monoxide/symptoms-causes/syc-20370642.

28. Marfin, Y.S.; Aleksakhina, E.L.; Merkushev, D.A.; Rumyantsev, E. V.; Tomilova, I.K. Interaction of BODIPY Dyes with the Blood Plasma Proteins. J. Fluoresc. 2016, 26, 255-261, https://doi.org/10.1007/s10895-015-1707-x.

29. Litvinov, R.I.; Faizullin, D.A.; Zuev, Y.F.; Weisel, J.W. The $\alpha$-Helix to $\beta$-Sheet Transition in Stretched and Compressed Hydrated Fibrin Clots. Biophys. J. 2012, 103, 1020-1027, https://doi.org/10.1016/j.bpj.2012.07.046.

30. Nashchekina, Y.A.; Starostina, A.A.; Trusova, N.A.; Sirotkina, M.Y.; Lihachev, A.I.; Nashchekin, A. V. Molecular and Fibrillar Structure Collagen Analysis by FTIR Spectroscopy. Journal of Physics: Conference Series 2020, 1697, p. 12053, https://iopscience.iop.org/article/10.1088/1742-6596/1697/1/012053/meta.

31. Kong, J.; Yu, S. Fourier Transform Infrared Spectroscopic Analysis of Protein Secondary Structures. Acta Biochim. Biophys. Sin. (Shanghai). 2007, 39, 549-559, https://doi.org/10.1111/j.1745-7270.2007.00320.x.

32. Zhmurov, A.; Kononova, O.; Litvinov, R.I.; Dima, R.I.; Barsegov, V.; Weisel, J.W. Mechanical Transition from $\alpha$-Helical Coiled Coils to $\beta$-Sheets in Fibrin(Ogen). J. Am. Chem. Soc. 2012, 134, 20396-20402, https://doi.org/10.1021/ja3076428.

33. Tutwiler; Singh; Litvinov; Bassani; Purohit; Weisel Fracture Resistance of Fibrin Clots. In Proceedings of the Arteriosclerosis, Thrombosis, Vascular Biology, Circulation 2019, 140, https://www.ahajournals.org/doi/abs/10.1161/circ.140.suppl_1.15649.

34. Jansen, K.A.; Zhmurov, A.; Vos, B.E.; Portale, G.; Hermida-Merino, D.; Litvinov, R.I.; Tutwiler, V.; Kurniawan, N.A.; Bras, W.; Weisel, J.W.; et al. Molecular Packing Structure of Fibrin Fibers Resolved by X-Ray Scattering and Molecular Modeling. Soft Matter 2020, 16, 8272-8283, https://doi.org/10.1039/d0sm00916d.

35. Sovova, Z.; Suttnar, J.; Dyr, J.E. Molecular Dynamic Simulations Suggest That Metabolite-Induced PostTranslational Modifications Alter the Behavior of the Fibrinogen Coiled-Coil Domain. Metabolites 2021, 11, 307, https://doi.org/10.3390/metabo11050307.

36. Nose, A.; Hojo, M.; Ueda, T. Effects of Salts, Acids, and Phenols on the Hydrogen-Bonding Structure of Water-Ethanol Mixtures. J. Phys. Chem. B 2004, 108, 798-804, https://doi.org/10.1021/jp0308312. 